\title{
An integrated production inventory model of deteriorating items subject to random machine breakdown with a stochastic repair time
}

\author{
Huynh Trung Luong ${ }^{\mathrm{a}}$ and Rubayet Karim ${ }^{\mathrm{b}^{*}}$
}

${ }^{a}$ Department of Industrial System Engineering, Asian Institute of Technology, Bangkok, Thailand ${ }^{b}$ Department of Industrial \& Production Engineering, Jessore University of Science \&Technology, Jessore, Bangladesh

CHRONICLE ABSTRACT

Article history:

Received April 262016

Received in Revised Format August 162016

Accepted September 182016

Available online

September 192016

Keywords:

Production- inventory model

Continuous review system

Stochastic repair time

Deteriorating item

Optimization

\begin{abstract}
In a continuous manufacturing environment where production and consumption occur simultaneously, one of the biggest challenges is the efficient management of production and inventory system. In order to manage the integrated production inventory system economically it is necessary to identify the optimal production time and the optimal production reorder point that either maximize the profit or minimize the cost. In addition, during production the process has to go through some natural phenomena like random breakdown of machine, deterioration of product over time, uncertainty in repair time that eventually create the possibility of shortage. In this situation, efficient management of inventory \& production is crucial. This paper addresses the situation where a perishable (deteriorated) product is manufactured and consumed simultaneously, the demand of this product is stable over the time, machine that produce the product also face random failure and the time to repair this machine is also uncertain. In order to describe this scenario more appropriately, the continuously reviewed Economic Production Quantity (EPQ) model is considered in this research work. The main goal is to identify the optimal production uptime and the production reorder point that ultimately minimize the expected value of total cost consisting of machine setup, deterioration, inventory holding, shortage and corrective maintenance cost.
\end{abstract}

\section{Introduction}

Inventory control has appeared as the most important application of operations research. Effective control of inventories can cut cost significantly, and contribute to the efficient flow of goods and services in the economy. Inventory theory is one of the main subfield of operations research to determine the optimal quantity and the order time. Nearly 100 years ago, Ford Harris first introduced the theory associated with inventory control and derived the famous economic order quantity (EOQ) formula. The EOQ formula, first developed by Harris, has been remarkably robust and it still provides effective approximate result for much more complex models. One of the key assumptions in EOQ model is that the entire lot size is delivered at the same time. This assumption holds only when products are obtained from outside

* Corresponding author

E-mail: rubayet26@gmail.com (R. Karim)

(C) 2017 Growing Science Ltd. All rights reserved.

doi: $10.5267 /$ j. ijiec.2016.9.004 
suppliers. When products are produced internally, the production rate is finite and EOQ model is not applicable, hence, another model, i.e., economic production quantity (EPQ) model is used instead of EOQ model. EPQ is now considered as a widely accepted production-inventory model that can be applied in industry. Based on the nature of the product an inventory system can be classified as perishable and nonperishable inventory systems. Both EOQ and EPQ models are used for controlling inventory of perishable and nonperishable products.

Perishable products are the products that can be used in a certain period (called product's lifetime) such as foodstuffs, medicines, chemicals, etc. There are mainly two kinds of products with perishable property. First, perishable products with a fixed lifetime period, these products perish after a certain period of time. Second, perishable products with random life time products may perish at any time after producing. For the perishable products with random lifetime, they can be deteriorated at any time after producing. In most cases it is assumed that this deterioration follows an exponential distribution. It means in every planning period, a fixed fraction of the inventory is lost or, in other words, the size of the inventory will decrease at an exponential rate. Exponential deterioration can be used to describe some real systems accurately. Also, exponential decay can provide a good approximation for fixed life perishable products. The greater quantity is produced, the more items perish. Thus, determining the policy for production and inventory for this kind of products is very important to reduce the total cost as well as to maximize the profit. In an integrated production inventory system, random breakdown of machine is an important phenomenon. This breakdown also has significant impact on inventory. Time to recover machine breakdown is also uncertain. As a result, inventory shortage may occur during a production cycle. Many research works have been executed so far on inventory modeling.

Weiss (1980) first developed an inventory model by considering continuous review system and assumed that demand follows a Poisson distribution. Later, Liu and Lian (1999) generalized the main results of Weiss. According to their assumption demand shortage is fully backordered and they generalized the model to a stationary renewal process instead of a Poisson demand. Gurler and Ozkaya (2003) made a necessary amendment of Liu and Lian results. Later, Gurler and Ozkaya (2008) developed their own model by considering the life span of a batch as a random variable. Berk and Gurler (2008) developed a general approach known as $(\mathrm{Q}, \mathrm{r})$ policy which is an optimal policy for many continuous review inventory systems of nonperishable items. Tekin (2001) ameliorated the problem to some extent by making necessary revisions of the $(\mathrm{Q}, \mathrm{R})$ policy by proposing a $(\mathrm{Q}, \mathrm{R}, \mathrm{T})$ policy. According to this policy, a refill order of amount $Q$ is placed every time the available inventory level falls to $r$, or when $T$ amounts of time have passed since the last occasion the inventory position reaches $Q$, whichever happens first.

Chiu and Wang (2007) developed an EPQ model with the consideration of scrap, rework and stochastic machine breakdowns. They assumed random breakdown of machine and no resumption (NR) policy in their proposed model. Then total production-inventory cost functions were derived respectively for both EPQ models with breakdown and without breakdown and these cost functions were integrated and renewal reward theorem was used to cope with the variable cycle length. The authors concluded that the optimal runtime falls within the range of bounds and is determined by using the bisection method that is based on the intermediate value theorem. Chiu et al. (2011) derived a mathematical model for solving manufacturing runtime problem with the consideration of constant demand rate, constant production rate, random defective rate and stochastic machine breakdown.

They assumed that number of machine breakdowns per year is a random variable and it follows a Poisson distribution, they also assumed that when a machine breakdown occurs, then it follows no resumption (NR) inventory control policy and time to repair machine is fixed. Total production-inventory cost functions are derived respectively for both EPQ models with breakdown, without breakdown and these cost functions are integrated and renewal reward theorem was applied for variable cycle length. He et al. (2010) developed a production inventory model of deteriorating items with the consideration of constant production rate, constant demand rate and constant deterioration rate. At first the authors derived 
inventory models for manufacturer's finished products and warehouse raw materials. From these models they developed an integrated inventory model for a single manufacturer. Finally, the authors come up with a solution procedure for the optimal replenishment schedule of raw materials and the optimal production plan of finished product. Rau et al. (2003) proposed an integrated production inventory model by considering one material supplier, one producer $\&$ one retailer for a perishable product with a constant demand rate. They assumed materials having the same decay rate with the finished product. The producer orders material from the material supplier at every fixed time interval, then produces finished goods and finally makes delivery to the retailer. The main target is to determine optimal material order quantity, production cycle and number of deliveries of finished goods from the producer to the retailer.

Yang and Wee (2003) developed an integrated production inventory model by incorporating multiple retailers. They derived a multi-lotsize production inventory model of perishable items with constant demand and production rates by considering the perspectives of the producer and the retailers. They presented a mathematical model subjected to a multi-lot-size production and distribution. In this research, the just in time (JIT) lot splitting concept from raw material supply to production and distribution is considered. It has been observed that the integration and lot-splitting effects with JIT implementation have contributed significantly to cost reduction. However, it is noted that the authors still assumed constant demand rates and no shortages in their model. Widyadana and Wee (2012) developed an economic production quantity (EPQ) model with the consideration of multiple production setups and rework. They assumed constant production, demand, rework and deteriorating rates in their proposed model. However, shortage is not allowed in their model and they also ignored the breakdown of the machine. The authors introduced $(m, 1)$ policy in their model. According to this policy, in one cycle a production facility can produce items in $m$ production setups and one rework setup. Finally, from the total inventory cost expression they derived expression for optimal number of production setups that minimize the total cost.

Lin and Gong (2006) considered the impact of random machine breakdowns on the classical economic production quantity (EPQ) model for an item subject to exponential decay and under a no-resumption (NR) inventory control policy. They assumed constant demand rate, finite production rate, fixed repair time and infinite planning horizon. They also assumed that time to deterioration of product and time to breakdown of the machine follow an exponential distribution. Total production-inventory cost function was derived for this EPQ model and the authors developed an expression for the optimal production uptime that helps to minimize the per unit time expected total cost. Widyadana and Wee (2011) extended the Lin and Gong model by considering repair time as stochastic variable instead of fixed repair time. They assumed constant demand, production and deterioration rates in their proposed model. The model assumes that machine repair time is stochastic and this time is independent of the machine breakdown. They analyzed two cases for a stochastic repair time: in the first case the repair time follows uniform distribution and in the second case the repair time follows an exponential distribution. Finally, the authors used classical optimization procedure to derive an optimal solution for the proposed model. The motivation of the research work presented in this paper comes from past research works of Widyadana and Wee (2011) and Lin and Gong (2006). In fact, Li and Gong (2006) derived their model by considering fixed repair time whereas, Widyadana and Wee (2011) derived their model for stochastic repair time but they did not depict all possible scenarios of the stochastic repair time. In this concern, this research gives more emphasis on stochastic repair time by taking into consideration all possible scenario of stochastic repair time. Specifically, since repair time is stochastic, high shortage may occur during the time of repairing operation. As a result, in order to minimize this high shortage production reorder point can play a vital role. This reorder point acts as a safety stock and prevents shortage.

None of the previous related research works realize the importance of the reorder point for an integrated production inventory model of perishable items. That's why production reorder point is incorporated in the proposed model in this paper. The structure of this paper contains five sections. The $1^{\text {st }}$ section discusses related literature review and motivation of the research. The $2^{\text {nd }}$ section defines the problem 
based on which the model is developed. The $3^{\text {rd }}$ section presents a mathematical model formulation $\&$ development. The $4^{\text {th }}$ section shows an example $\&$ sensitivity analysis. Finally, the last section concludes the research with findings and recommendations.

\section{Problem description}

In an integrated production inventory system, both production and consumption occur simultaneously during the period of production and there is a continuous gradual addition to stock (finite replenishment rate) over the production period. This stock is depleted during the non-production time (that's why it is called inventory depletion time) due to deterioration and constant demand rate. During a production period machine always experience breakdown before the completion of the full production cycle and it takes time to recover the machine to the working state. This recover time or repair time depends on the nature of failure or breakdown of the machine. If machine faces major failure, then it takes significant time to repair and if this time exceeds the inventory depletion time, then shortage will occur due to the constant consumption rate during the repair time. In order to cope with this situation, it is necessary to establish a production reorder point that can help to minimize the expected shortage during the stochastic repair time. When the inventory level reaches this reorder point or inventory level is lower than the reorder point, then a new production run will be started. As the product is a perishable product and it is deteriorated over the time, so if we set high level for reorder point then it also increases expected deterioration amount of product. So the production reorder point must be defined in such a way that it not only help to minimize the expected shortage cost but also help to minimize the expected deteriorating cost. Moreover, in a finite replenishment rate situation, another important decision variable is the production run/up time, if runtime is long enough, then it creates high stock (inventory) over the production period.

As a result, it not only leads to increase in inventory holding cost, but also increases in deteriorating cost. In fact, the deterioration of a product starts immediately after it is received into inventory. However, if the production setup is very expensive compared to inventory holding and deteriorating cost, then it is better to go for long production run instead of increasing number of setups. So production up/run time must also be defined in such a way that the expected total cost consist of expected inventory holding cost, expected deteriorating cost \& fixed production setup cost is minimized. In order to understand the problem clearly, it is necessary to consider three cases for this research. These three cases are:

1. Case I: There is no machine breakdown during a planned production period of length $\tau$, so repair time $t_{r}=0$.

2. Case II: There is a machine breakdown during a planned production period and repair time $t_{r}<T_{2}$, in which $T_{2}$ is the time at which inventory reaches the reorder point, $R$.

3. Case III (A): There is a machine breakdown during a planned production period, but the repair time $t_{r}>T_{2}$.However shortage does not occur.

4. Case III (B): There is a machine breakdown during a planned production period and repair time $t_{r}>>T_{2}$ and shortage will occur due to long repair time.

By considering the cases shown below, a mathematical model will be derived. At first, expected total cost expressions both for breakdown \& no breakdown situation are developed. Similarly, expressions for expected cycle length both for no breakdown (Case I) and breakdown situation (CaseII, CaseIII (A), CaseIII (B)) will be developed. Finally from these expected total cost and expected cycle length expressions the expected total cost per unit time is determined.

\section{Mathematical Model Development}

A mathematical model has been developed in order to optimize the total cost function with the consideration of two decision variables: Production uptime $(\tau)$ and Reorder point $(\mathrm{R})$. The following notations are used in the model: 


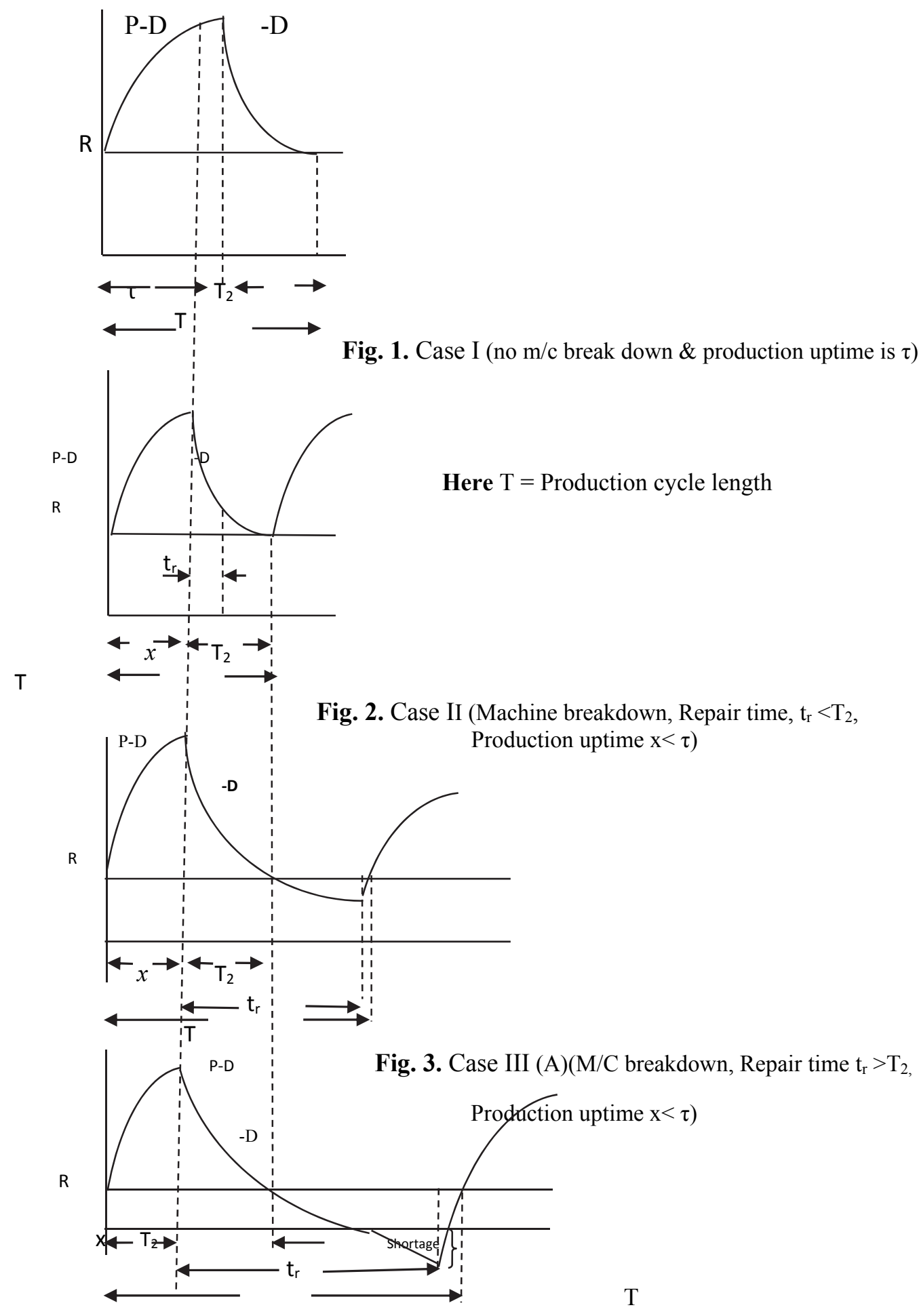

Fig. 4. Case III (B) (M/C breakdown, Repair time $t_{r}>>T_{2}$, Production uptime $\left.x<\tau\right)$

\subsection{Notations}

$I_{1}\left(t_{1}\right)$ inventory level function during the production period of a cycle.

$I_{2}\left(t_{2}\right)$ inventory level function during the non-production period of a cycle.

$T_{2}{ }^{(l)}$ time at which inventory level reaches a reorder point when there is no breakdown of $\mathrm{m} / \mathrm{c}$.

$T_{2}{ }^{(2)}$ time at which inventory level reaches a reorder point when there is breakdown of $\mathrm{m} / \mathrm{c}$.

$T_{3} \quad$ time at which inventory level becomes empty 
$t_{r} \quad$ time to repair a machine after failure, a continuous random variable that follows an exponential distribution. It varies from 0 to $\infty$, i.e $0 \leq \mathrm{t}_{\mathrm{r}}<\infty$.

$T \quad$ cycle length

$P \quad$ production rate

$D \quad$ demand rate

$\theta \quad$ deterioration rate(unit/unit time)

$x$ time to break down of a $\mathrm{m} / \mathrm{c}$, a continuous random variable that follows an exponential distribution

$\tau \quad$ production uptime when no machine failure occurs, a decision variable

$K \quad$ setup cost

$H \quad$ per unit per unit time holding cost

$\delta \quad$ unit cost of shortage

$\pi \quad$ per unit deterioration cost

$M \quad$ machine repair cost

$S \quad$ shortage quantity

$T^{\prime} \quad$ non production period

$T_{p} \quad$ production period

$\mu \quad$ average number of $\mathrm{m} / \mathrm{c}$ breakdowns per unit time

$\lambda \quad$ average number of $\mathrm{m} / \mathrm{c}$ repair per unit time

$R \quad$ reorder point, a decision variable

$L \quad$ deterioration quantity

$x^{\prime} \quad$ time at which inventory reaches a reorder point after repairing of $\mathrm{m} / \mathrm{c}$ in Case IIIA

$x^{\prime \prime} \quad$ time at which inventory reaches a reorder point after repairing of $\mathrm{m} / \mathrm{c}$ in Case IIIB

\subsection{Assumptions}

The mathematical model in this section is developed by considering the following assumptions.

1. The demand rate of the product is constant and known.

2. The time to break down of machine follows an exponential distribution with parameter $\mu$.

3. Deterioration of inventory has a constant rate $\theta$.

4. Unsatisfied demands during repair time are considered as shortage.

5. Production up time \& reorder point will not vary from one cycle to another cycle.

6. Setup time of machine prior to the start of a new production run is negligible $\&$ assumed to be zero.

7. The time to repair a machine follows an exponential distribution with parameter $\lambda$.

8. The production rate is greater than demand rate.

\subsection{The objective function}

The main objective of the model is to determine the optimum value of reorder point, $\mathrm{R} \&$ production up time $\tau$ so as to minimize the expected total cost per unit time.

Minimize

Expected total cost per unit time $=\frac{E[I] * H+E[S] * \delta+E[L] * \pi+K+E[M]}{E[T]}$

subject to

$R \geq 0 \quad \& \quad \tau \geq 0$.

where,

$\mathrm{E}[\mathrm{I}]=$ expected time cumulative inventory holding in a cycle. 
$\mathrm{E}[\mathrm{S}]=$ expected shortage in a cycle. $\mathrm{E}[\mathrm{L}]=$ expected deterioration quantity in a cycle.

$\mathrm{E}[\mathrm{M}]=$ expected maintenance cost in a cycle. $\mathrm{K}=$ setup cost in a cycle.

$\mathrm{E}[\mathrm{T}]=$ expected cycle length.

The expressions of the above expected cost components and expected cycle length are derived in the following sections. At first, the mathematical model is formulated by considering repair time as a stochastic variable. This stochastic nature of repair time is shown by considering all the possible cases of an integrated production inventory system which is given in the following figures. In Fig. 5, when the inventory level reaches to $R$ then new production run will start for a time period of $\tau$ units given that the machine has not experienced any failure. Inventory is accumulated at a rate of $P-D$ and there is also a constant deterioration rate $\theta$ for the accumulated inventory. At time $t=\tau$ units, inventory level reaches to its maximum level, $I_{1}(\tau)$ and production run is stopped. The maximum on hand inventory level is then consumed both for demand and deterioration and a new production run will start again when the inventory level reaches the reorder point, R. But sometimes machine experience breakdown (Figs. (6$8)$ ) before the completion of the full production cycle and this breakdown occurs at time $t=x$ with $x<\tau$. As a result, the production run is stopped immediately and inventory reaches to its maximum level, $I_{1}(x)$.

The new production run will start after repairing of machine this repair time is stochastic. Sometimes repair time, $\mathrm{t}_{\mathrm{r}}$ is shorter than $T_{2}{ }^{(2)}$ (Fig. 6) and new run will start at time, $\mathrm{T}_{2}{ }^{(2)}$. Sometimes repair time, $\mathrm{t}_{\mathrm{r}}$ is longer than $T_{2}^{(2)}$ but shorter than $T_{3}$ (Fig. 7) \& production run starts immediately at $t_{r}$.More often repair time, $t_{\mathrm{r}}$ is longer than inventory depletion time, i.e., $\mathrm{t}_{\mathrm{r}}>\mathrm{T}_{3}$. (Fig. 8) and this case shortage occurs due to long repair time. From figures, $T$ represents cycle length and it is defined by the time durations between two consecutive starting points of production at reorder point, $R$. In this model, products assumed to follow an exponential deterioration process, so the inventory level, both for production \& non- production period of an integrated production inventory system at time $t$ can be derived by the following differential equations:

$$
\begin{aligned}
& \frac{d I_{1}\left(t_{1}\right)}{d t_{1}}+\theta \cdot I_{1}\left(t_{1}\right)=P-D \\
& \frac{d I_{2}\left(t_{2}\right)}{d t_{2}}+\theta \cdot I_{2}\left(t_{2}\right)=-D
\end{aligned}
$$

From the figures given above, it can be seen that at time $t_{1}=0, I_{1}\left(t_{1}\right)=R$ and at time $t_{2}=T_{2}{ }^{(1)}, I_{2}\left(t_{2}\right)=$ $I_{2}\left(T_{2}^{(l)}\right)=R$. Eq. (2) and Eq. (3) are being solved by using these boundary conditions and these solutions represent the inventory level at specified time. These solutions are shown below.

$$
\begin{aligned}
& I_{1}\left(t_{1}\right)=\frac{P-D}{\theta}+\left(R-\frac{P-D}{\theta}\right) e^{-\theta t_{1}} \\
& I_{2}\left(t_{2}\right)=\frac{-D}{\theta}+\left\{\left(\frac{D}{\theta}+R\right) e^{\theta T_{2}^{(1)}}\right\} e^{-\theta t_{2}}
\end{aligned}
$$

But cases having random machine breakdown that is Case-II, Case-IIIA \& Case-IIIB, at time $t_{2}=T_{2}^{(2)}$, $I_{2}\left(t_{2}\right)=I_{2}\left(T_{2}{ }^{(2)}\right)=R$ and using this boundary condition the solution of Eq. (3) for non-production period is achieved which is shown below.

$$
I_{2}^{\prime}\left(t_{2}\right)=-\frac{D}{\theta}+\left\{\left(\frac{D}{\theta}+R\right) e^{\theta T_{2}^{(2)}}\right\} e^{-\theta t_{2}}
$$




\subsection{Expected inventory holding cost}

E [I] represents the expected inventory carried per cycle time. In order to determine the expected inventory holding quantity in a cycle it is necessary to measure the time cumulative inventory. The time cumulative inventory can be expressed by the following function.

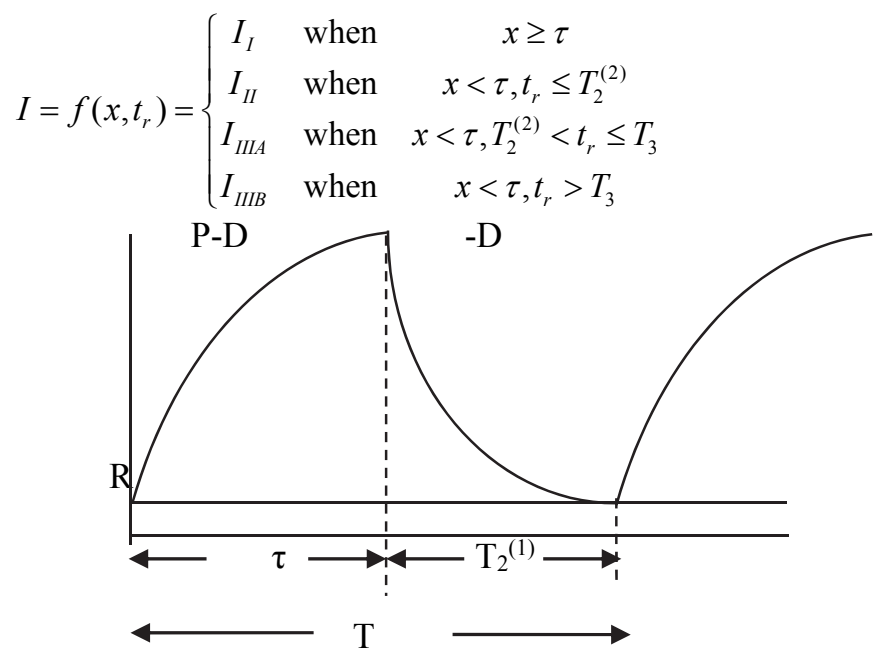

Fig. 5. Case $\mathrm{I}$
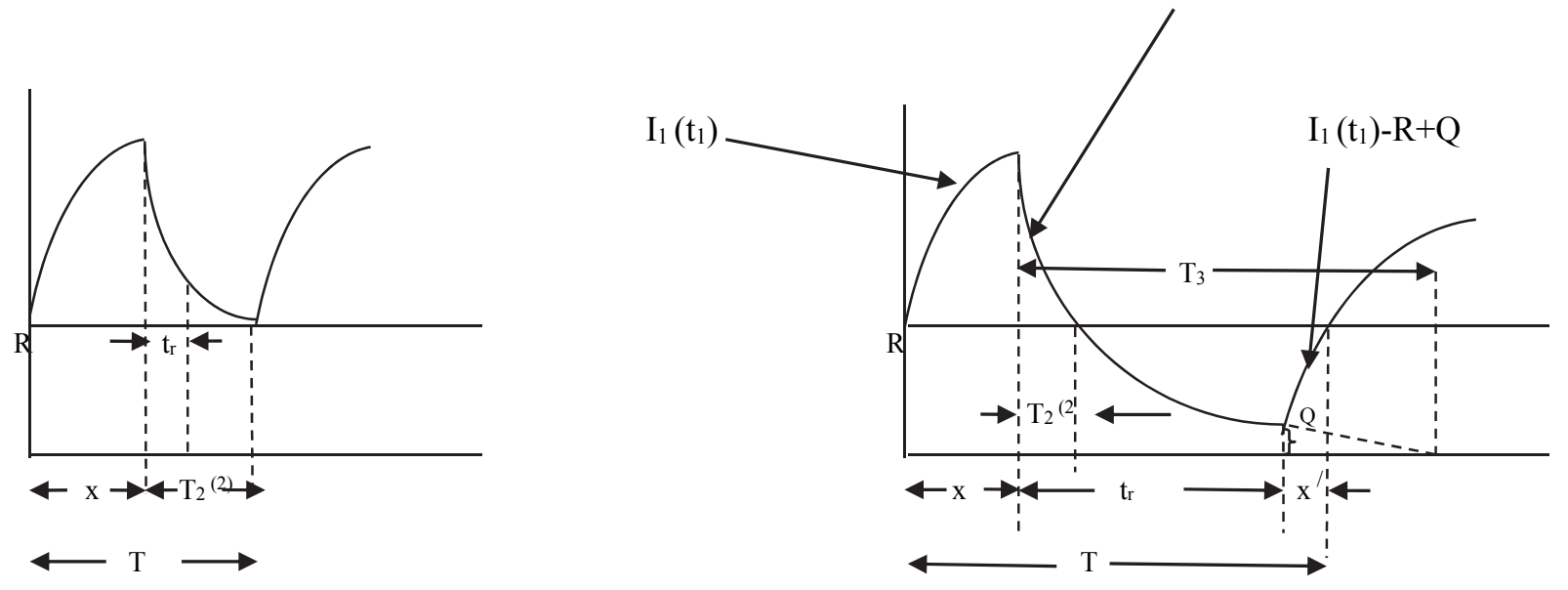

Fig. 6. Case II

Fig. 7. Case IIIA

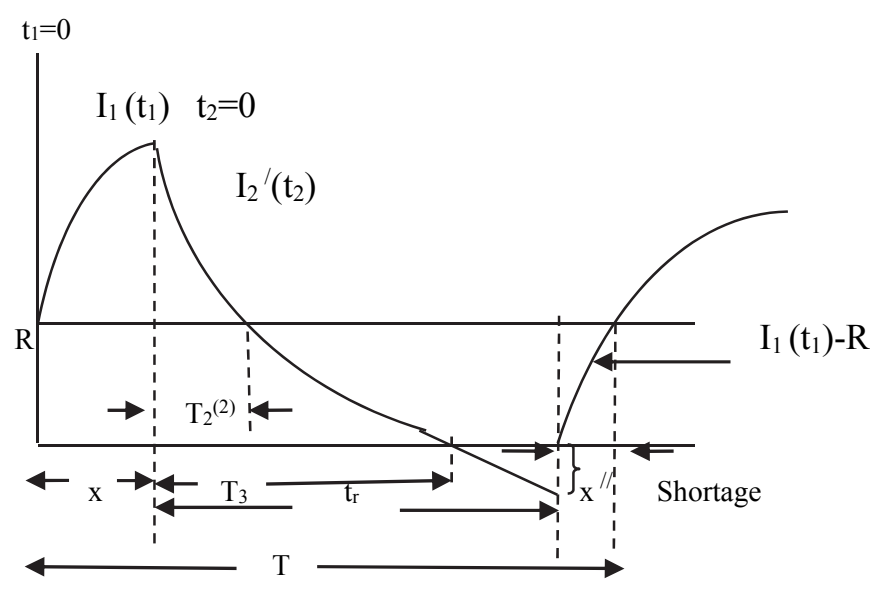

Fig. 8. Case IIIB 
II, III, IIIIA, IIIIB represents time cumulative inventory for Case-I, Case-II, Case-IIIA \& Case-IIIB respectively. These time cumulative inventories for different cases are shown in the above mentioned figures. Now the time cumulative inventory for all possible cases is:

$$
\begin{aligned}
& I_{I}=\int_{0}^{\tau} I_{1}\left(t_{1}\right) d t_{1}+\int_{0}^{T_{2}^{(1)}} I_{2}\left(t_{2}\right) d t_{2} \quad \text { (Case-I) } \\
& I_{I}=\frac{P-D}{\theta} \tau+\frac{1}{\theta}\left(R-\frac{P-D}{\theta}\right)\left(1-e^{-\theta \tau}\right)-\frac{D}{\theta} T_{2}^{(1)}+\left(R+\frac{D}{\theta}\right) e^{\theta T_{2}^{(1)}} \frac{1}{\theta}\left(1-e^{-\theta T_{2}^{(1)}}\right) \\
& I_{I I}=\int_{0}^{x} I_{1}\left(t_{1}\right) d t_{1}+\int_{0}^{T_{2}^{(2)}} I_{2}^{\prime}\left(t_{2}\right) d t_{2} \quad(\text { Case-II) } \\
& I_{I I}=\frac{P-D}{\theta} x+\frac{1}{\theta}\left(R-\frac{P-D}{\theta}\right)\left(1-e^{-\theta x}\right)-\frac{D}{\theta} T_{2}^{(2)}+\left(R+\frac{D}{\theta}\right) e^{\theta T_{2}^{(2)}} \frac{1}{\theta}\left(1-e^{-\theta T_{2}^{(2)}}\right) \\
& I_{I I I A}=\int_{0}^{x} I_{1}\left(t_{1}\right) d t_{1}+\int_{0}^{t_{r}} I_{2}^{\prime}\left(t_{2}\right) d t_{2}+\int_{0}^{x /}\left\{I_{1}\left(t_{1}\right)-R+Q\right\} d t_{1} \text { (Case-IIIA) } \\
& I_{I I I A}=\frac{P-D}{\theta} x+\frac{1}{\theta}\left(R-\frac{P-D}{\theta}\right)\left(1-e^{-\theta x}\right)-\frac{D}{\theta} t_{r}+\left(R+\frac{D}{\theta}\right) e^{\theta T_{2}^{(2)}} \frac{1}{\theta}\left(1-e^{-\theta t_{r}}\right)+\frac{P-D}{\theta} x^{\prime}+ \\
& \left(R-\frac{P-D}{\theta}\right) \frac{1}{\theta}\left(1-e^{-\theta x /}\right)-R x^{\prime}-\frac{D}{\theta} x^{\prime}+\left(R+\frac{D}{\theta}\right) e^{\theta T_{2}^{(2)}} e^{-\theta t_{r}} x^{\prime} \\
& I_{I I I B}=\int_{0}^{x} I_{1}\left(t_{1}\right) d t_{1}+\int_{0}^{T_{3}} I_{2}^{\prime}\left(t_{2}\right) d t_{2}+\int_{0}^{x / /}\left\{I_{1}\left(t_{1}\right)-R\right\} d t_{1} \text { (Case-IIIB) } \\
& I_{I I I B}=\frac{P-D}{\theta} x+\frac{1}{\theta}\left(R-\frac{P-D}{\theta}\right)\left(1-e^{-\theta x}\right)-\frac{D}{\theta} T_{3}+\left(R+\frac{D}{\theta}\right) e^{\theta T_{2}^{(2)}} \frac{1}{\theta}\left(1-e^{-\theta T_{3}}\right)+\left(\frac{P-D}{\theta}-\right. \\
& R) x^{/ /}+\left(R-\frac{P-D}{\theta}\right) \frac{1}{\theta}\left(1-e^{-\theta x / /}\right)
\end{aligned}
$$

By taking into consideration of all possible cases (shown in Figs. (5-8)), the following relationships are also obtained.

$$
\begin{aligned}
& T_{2}^{(1)}=\frac{1}{\theta} \ln \frac{P+(\mathrm{R} \theta-P+D) \mathrm{e}^{-\theta \tau}}{\mathrm{R} \theta+D} \\
& T_{2}^{(2)}=\frac{1}{\theta} \ln \frac{P+(\mathrm{R} \theta-P+D) \mathrm{e}^{-\theta \mathrm{x}}}{\mathrm{R} \theta+D} \\
& \mathrm{x}^{\prime}=\frac{1}{\theta} \ln \frac{\left(\mathrm{R}-\frac{\mathrm{P}-\mathrm{D}}{\theta}\right)}{2 \mathrm{R}-\frac{\mathrm{P}-\mathrm{D}}{\theta}+\frac{\mathrm{D}}{\theta}-\left\{\left(\mathrm{R}+\frac{\mathrm{D}}{\theta}\right) \mathrm{e}^{\theta \mathrm{T}_{2}^{(2)}}\right\} \mathrm{e}^{-\theta \mathrm{t}_{\mathrm{r}}}} \\
& \mathrm{x}^{\prime /}=\frac{1}{\theta} \ln \frac{\mathrm{R} \theta-\mathrm{P}+\mathrm{D}}{2 \mathrm{R} \theta-\mathrm{P}+\mathrm{D}} \\
& T_{3}=\frac{1}{\theta} \ln \frac{P+(\mathrm{R} \theta-P+D) \mathrm{e}^{-\theta \mathrm{x}}}{D}
\end{aligned}
$$

Now, the expected inventory carried per cycle can be expressed by the expression given below:

$\mathrm{E}[\mathrm{I}]=\int_{x=\tau}^{\infty} I_{I} f_{x}(x) d x+\int_{x=0}^{\tau}\left\{\int_{t_{r}=0}^{T_{2}^{(2)}} I_{I I} f_{t_{r}}\left(t_{r}\right) d t_{r}+\int_{t_{r}=T_{2}^{(2)}}^{T_{3}} I_{I I I A} f_{t_{r}}\left(t_{r}\right) d t_{r}+\int_{t_{r}=T_{3}}^{\infty} I_{I I I B} f_{t_{r}}\left(t_{r}\right) d t_{r}\right\} f_{x}(x) d x$

So the expected inventory holding cost per cycle $=$ expected inventory carried in a cycle, $E[I] \times H$

$=\left[\int_{x=\tau}^{\infty} I_{I} f_{x}(x) d x+\int_{x=0}^{\tau}\left\{\int_{t_{r}=0}^{T_{2}^{(2)}} I_{I I} f_{t_{r}}\left(t_{r}\right) d t_{r}+\int_{t_{r}=T_{2}^{(2)}}^{T_{3}} I_{I I I A} f_{t_{r}}\left(t_{r}\right) d t_{r}+\int_{t_{r}=T_{3}}^{\infty} I_{I I I B} f_{t_{r}}\left(t_{r}\right) d t_{r}\right\} f_{x}(x) d x\right] * H$

Assume that $\mathrm{M} / \mathrm{C}$ breakdown time $x$ is a continuous random variable that follows an exponential distribution with parameter $\mu$. So the exponential probability density function is given as $\mathrm{f}_{\mathrm{x}}(\mathrm{x})=\mu$. $\mathrm{e}^{-\mu \mathrm{x}}$ for $\mu>0$. Similarly, $\mathrm{M} / \mathrm{C}$ repair time $\mathrm{t}_{\mathrm{r}}$ is a random variable that follows an exponential distribution with parameter $\lambda$. So the exponential probability density function is given as $f_{\operatorname{tr}}\left(t_{r}\right)=\lambda$. $e^{-\lambda \operatorname{tr}}$ for $\lambda>0$. $H$ denotes the inventory holding cost per unit per unit time. Each individual integral component of expected 
inventory holding quantity is determined. After numerous calculations the following expressions are achieved.

1. $\int_{x=\tau}^{\infty} I_{I} f_{x}(x) d x=\left\{\frac{P-D}{\theta} \tau+\frac{1}{\theta}\left(R-\frac{P-D}{\theta}\right)\left(1-e^{-\theta \tau}\right)-\frac{D}{\theta} T_{2}^{(1)}+\left(R+\frac{D}{\theta}\right) \frac{1}{\theta} e^{\theta T_{2}^{(1)}}\left(1-e^{-\theta T_{2}^{(1)}}\right)\right\} e^{-\mu \tau}$

$2 \cdot \int_{x=0}^{\tau} \int_{t_{r}=0}^{T_{2}^{(2)}} I_{I I} f_{t_{r}}\left(t_{r}\right) d t_{r} f_{x}(x) d x$

$=\int_{x=0}^{\tau}\left[\left\{\frac{P-D}{\theta} x+\frac{1}{\theta}\left(R-\frac{P-D}{\theta}\right)\left(1-e^{-\theta x}\right)-\frac{D}{\theta} T_{2}^{(2)}+\left(R+\frac{D}{\theta}\right) \frac{1}{\theta} e^{\theta T_{2}^{(2)}}\left(1-e^{-\theta T_{2}^{(2)}}\right)\right\}\left(1-e^{-\lambda T_{2}^{(2)}}\right)\right] \mu e^{-\mu x} d x$

3. $\int_{x=0}^{\tau} \int_{t_{r}=T_{2}^{(2)}}^{T_{3}} I_{I I I A} f_{t_{r}}\left(t_{r}\right) d t_{r} f_{x}(x) d x$

$=\int_{x=0}^{\tau}\left[\left\{\frac{P-D}{\theta} x+\frac{1}{\theta}\left(R-\frac{P-D}{\theta}\right)\left(1-e^{-\theta x}\right)\right\}\left(e^{-\lambda T_{2}^{(2)}}-e^{-\lambda T_{3}}\right)-\frac{D}{\theta}\left\{-T_{3} e^{-\lambda T_{3}}+T_{2}^{(2)} e^{-\lambda T_{2}^{(2)}}-\frac{1}{\lambda}\left(e^{-\lambda T_{3}}-\right.\right.\right.$

$\left.\left.e^{-\lambda T_{2}^{(2)}}\right)\right\}+\left(R+\frac{D}{\theta}\right) \frac{1}{\theta} e^{\theta T_{2}^{(2)}}\left(e^{-\lambda T_{2}^{(2)}}-e^{-\lambda T_{3}}\right)+\left(R+\frac{D}{\theta}\right) \frac{1}{\theta} e^{\theta T_{2}^{(2)}}\left(\frac{\lambda}{\theta+\lambda} e^{-(\lambda+\theta) T_{3}}\right.$

$\left.\left.-\frac{\lambda}{\theta+\lambda} e^{-(\lambda+\theta) T_{2}^{(2)}}\right)\right] \mu e^{-\mu x} d x+\int_{x=0}^{\tau} \int_{t_{r}=T_{2}^{(2)}}^{T_{3}}\left\{\frac{P-D}{\theta} x^{\prime}+\frac{1}{\theta}\left(R-\frac{P-D}{\theta}\right)\left(1-e^{-\theta x^{\prime}}\right)-R x^{\prime}-\frac{D}{\theta} x^{\prime}+(R+\right.$

$\left.\left.\frac{D}{\theta}\right) e^{\theta T_{2}^{(2)}} e^{-\theta t_{r}} x^{\prime}\right\} \lambda e^{-\lambda t_{r}} d t_{r} \mu e^{-\mu x} d x$

4. $\int_{x=0}^{\tau} \int_{t_{r}=T_{3}}^{\infty} I_{I I I B} f_{t_{r}}\left(t_{r}\right) d t_{r} f_{x}(x) d x$

$=\int_{x=0}^{\tau}\left[\left\{\frac{P-D}{\theta} x+\frac{1}{\theta}\left(R-\frac{P-D}{\theta}\right)\left(1-e^{-\theta x}\right)-\frac{D}{\theta} T_{3}+\left(R+\frac{D}{\theta}\right) \frac{1}{\theta} e^{\theta T_{2}^{(2)}}\left(1-e^{-\theta T_{3}}\right)+\left(\frac{P-D}{\theta}-R\right) x^{/ /}+\right.\right.$

$\left.\left.\frac{1}{\theta}\left(R-\frac{P-D}{\theta}\right)\left(1-e^{-\theta x / /}\right)\right\} e^{-\lambda T_{3}}\right] \mu e^{-\mu x} d x$

Finally, as it is not possible to solve all the above expressions analytically so numerical integrations are done by using Matlab. In order to achieve the expected inventory holding cost, the value of $\mathrm{T}_{2}{ }^{(1)}, \mathrm{T}_{2}{ }^{(2)} \&$ $\mathrm{T}_{3}$ from the Eq. (9), Eq. (10) and Eq. (13) is replaced in expected inventory holding cost equation., moreover the value of $\mathrm{x}^{\prime} \& \mathrm{x}^{\prime /}$ from the Eq. (11) and Eq. (12) is also replaced in expected inventory holding cost expression \& finally numerical integration is done.

\subsection{Expected shortage cost}

E [S] represents the expected shortage quantity carried in a cycle. The shortage quantity, S can be expressed by the following function \& this shortage quantity is shown in the following Fig 9.

$$
S=f\left(x, t_{r}\right)=\left\{\begin{array}{ccc}
0 & \text { when } & x \geq \tau \\
0 & \text { when } & x<\tau, t_{r} \leq T_{2}^{(2)} \\
0 & \text { when } & x<\tau, T_{2}^{(2)}<t_{r} \leq T_{3} \\
D\left(t_{r}-T_{3}\right) & \text { when } & x<\tau, t_{r}>T_{3}
\end{array}\right.
$$

So the expected shortage quantity, $E[S]=\int_{0}^{\tau} \int_{t_{r}=T_{3}}^{\infty} D\left(t_{r}-T_{3}\right) f_{t_{r}}\left(t_{r}\right) d t_{r} f_{x}(x) d x$

$$
=\int_{0}^{\tau} \int_{t_{r}=T_{3}}^{\infty} D\left(t_{r}-T_{3}\right) \lambda e^{-\lambda t_{r}} d t_{r} \mu e^{-\mu x} d x=\frac{\mu D}{\lambda} \int_{0}^{\tau} e^{-\lambda T_{3}} e^{-\mu x} d x
$$

So the expected shortage cost in a cycle is $\left(\frac{\mu D}{\lambda} \int_{0}^{\tau} e^{-\lambda T_{3}} e^{-\mu x} d x\right) . \delta$. Here $\delta$ denotes per unit shortage cost. 


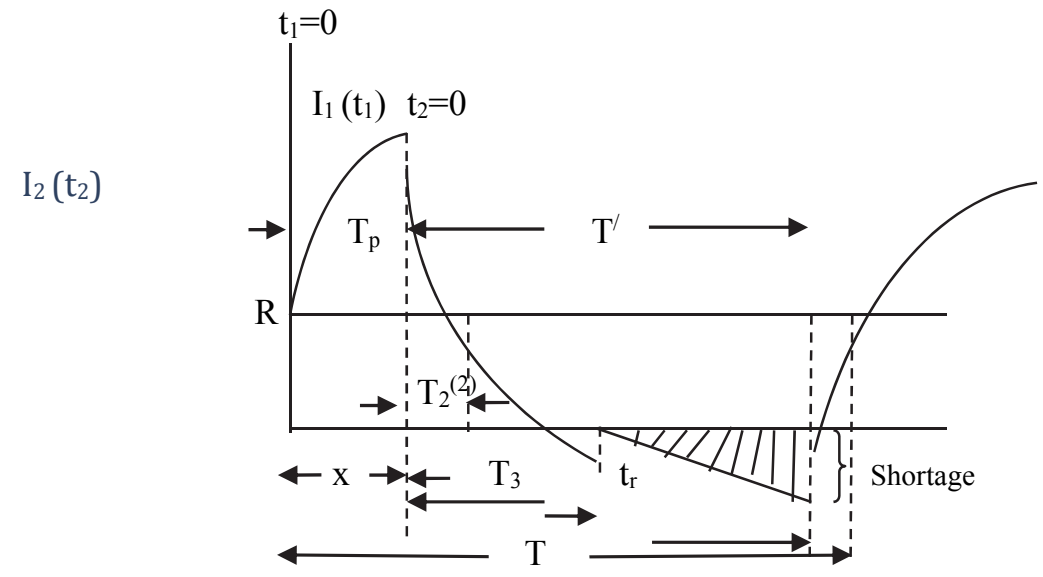

Fig. 9. Shortage situation

\subsection{Expected deteriorating cost}

The number of deteriorating quantities generated in a cycle can be obtained by subtracting the number of units used to meet the demand in a cycle from the number of units produced in a cycle. Also demand is not considered for shortage period. Demand during shortage period is considered as lost sales. Let L represents the deteriorating quantity. So the deteriorating quantity, L can be expressed by the following function

$$
L=f\left(x, t_{r}\right)=\left\{\begin{array}{ccc}
P . \tau-D\left(\tau+T_{2}^{(1)}\right) & \text { when } & x \geq \tau \\
P . x-D\left(\tau+T_{2}^{(2)}\right) & \text { when } & x<\tau, t_{r} \leq T_{2}^{(2)} \\
P\left(x+x^{\prime}\right)-D\left(x+t_{r}+x^{\prime}\right) & \text { when } & x<\tau, T_{2}^{(2)}<t_{r} \leq T_{3} \\
P\left(x+x^{\prime \prime}\right)-D\left(x+T_{3}+x^{\prime \prime}\right) & \text { when } & x<\tau, t_{r}>T_{3}
\end{array}\right.
$$

So, the expected deteriorating quantity in a cycle,

$$
\begin{aligned}
\mathrm{E}[\mathrm{L}]= & \int_{\tau}^{\infty}\left\{\mathrm{P} \cdot \tau-\mathrm{D}\left(\tau+T_{2}^{(1)}\right)\right\} f_{x}(x) d x+\int_{0}^{\tau} \int_{t_{r}=0}^{T_{2}^{(2)}}\left\{\mathrm{P} \cdot \mathrm{x}-\mathrm{D}\left(\mathrm{x}+T_{2}^{(2)}\right)\right\} f_{t_{r}}\left(t_{r}\right) d t_{r} f_{x}(x) d x \\
& +\int_{0}^{\tau} \int_{t_{r}=T_{2}^{(2)}}^{T_{3}}\left\{\mathrm{P}\left(\mathrm{x}+\mathrm{x}^{\prime}\right)-\mathrm{D}\left(\mathrm{x}+t_{r}+\mathrm{x}^{\prime}\right)\right\} \cdot f_{t_{r}}\left(t_{r}\right) d t_{r} f_{x}(x) d x+\int_{0}^{\tau} \int_{t_{r}=T_{3}}^{\infty}\left\{\mathrm{P}\left(\mathrm{x}+\mathrm{x}^{/ /}\right)-\right. \\
& \left.\mathrm{D}\left(\mathrm{x}+T_{3}+\mathrm{x} / /\right)\right\} f_{t_{r}}\left(t_{r}\right) d t_{r} f_{x}(x) d x \\
= & \left\{\mathrm{P} \cdot \tau-\mathrm{D}\left(\tau+T_{2}^{(1)}\right)\right\} \mathrm{e}^{-\mu \tau}+\int_{0}^{\tau} \int_{t_{r}=T_{2}^{(2)}}^{T_{3}}\left\{\mathrm{P}\left(\mathrm{x}+\mathrm{x}^{\prime}\right)-\mathrm{D}\left(\mathrm{x}+t_{r}+\mathrm{x}^{\prime}\right)\right\} \cdot \lambda \mathrm{e}^{-\lambda \mathrm{t}_{\mathrm{r}}} d t_{r} \mu \mathrm{e}^{-\mu \mathrm{x}} d x \\
& +\int_{0}^{\tau}\left[\left\{\mathrm{P} \cdot \mathrm{x}-\mathrm{D}\left(\mathrm{x}+T_{2}^{(2)}\right)\right\}\left(1-\mathrm{e}^{-\lambda \mathrm{T}_{2}^{(2)}}\right)+\left\{\mathrm{P}(\mathrm{x}+\mathrm{x} / /)-\mathrm{D}\left(\mathrm{x}+T_{3}+\right.\right.\right. \\
& \left.\left.\left.\mathrm{x}^{/ /}\right)\right\} \mathrm{e}^{-\lambda \mathrm{T}_{3}}\right] \mu \mathrm{e}^{-\mu \mathrm{x}} d x
\end{aligned}
$$

So the expected deteriorating cost in a cycle is

$$
\begin{aligned}
\mathrm{E}[\mathrm{L}] . \pi= & {\left[\left\{\mathrm{P} \cdot \tau-\mathrm{D}\left(\tau+T_{2}^{(1)}\right)\right\} \mathrm{e}^{-\mu \tau}+\int_{0}^{\tau} \int_{t_{r}=T_{2}^{(2)}}^{T_{3}}\left\{\mathrm{P}\left(\mathrm{x}+\mathrm{x}^{\prime}\right)-\mathrm{D}\left(\mathrm{x}+t_{r}+\mathrm{x}^{\prime}\right)\right\} \cdot \lambda \mathrm{e}^{-\lambda \mathrm{t}_{\mathrm{r}}} d t_{r} \mu \mathrm{e}^{-\mu \mathrm{x}} d x\right.} \\
& +\int_{0}^{\tau}\left[\left\{\mathrm{P} \cdot \mathrm{x}-\mathrm{D}\left(\mathrm{x}+T_{2}^{(2)}\right)\right\}\left(1-\mathrm{e}^{-\lambda \mathrm{T}_{2}^{(2)}}\right)+\left\{\mathrm{P}\left(\mathrm{x}+\mathrm{x}^{/ /}\right)-\mathrm{D}\left(\mathrm{x}+T_{3}+\right.\right.\right. \\
& \left.\left.\left.\left.\mathrm{x}^{/ /}\right)\right\} \mathrm{e}^{-\lambda \mathrm{T}_{3}}\right] \mu \mathrm{e}^{-\mu \mathrm{x}} d x\right] . \pi
\end{aligned}
$$

$\Pi$ denotes cost of a deteriorated item. 
3.7 Repair cost \& setup cost per cycle

$M$ represents machine repair cost. So $M$ can be expressed by the following function,

$M=\left\{\begin{array}{ccc}0 & \text { when } & x \geq \tau \\ M & \text { when } & x<\tau\end{array}\right.$

So the expected machine repair cost, $E[M]=0 . P(x \geq \tau)+M \cdot P(x<\tau)=\mathrm{M} \cdot \int_{x=0}^{\tau} \mu \mathrm{e}^{-\mu \mathrm{x}} d x=\mathrm{M} \cdot\left(1-\mathrm{e}^{-\mu \tau}\right)$

Machine setup cost is fixed and this cost is represented by $K$. So machine setup cost in a cycle is $K$.

\subsection{Expected cycle length}

The cycle length is the summation of production period \& non production period. Let, $T$ represents the cycle length (Figs. (5-8)). The value of $T$ can be expressed by the following function

$$
T=f\left(x, t_{r}\right)=\left\{\begin{array}{ccc}
\tau+T_{2}^{(1)} & \text { when } & x \geq \tau \\
x+T_{2}^{(2)} & \text { when } & x<\tau, t_{r} \leq T_{2}^{(2)} \\
x+t_{r}+x^{\prime} & \text { when } & x<\tau, T_{2}^{(2)}<t_{r} \leq T_{3} \\
x+t_{r}+x^{\prime \prime} & \text { when } & x<\tau, t_{r}>T_{3}
\end{array}\right.
$$

So the expected cycle length,

$$
\begin{gathered}
E[T]=\int_{\tau}^{\infty}\left(\tau+T_{2}^{(1)}\right) \cdot f_{x}(x) d x+\int_{0}^{\tau} \int_{t_{r}=0}^{T_{2}^{(2)}}\left(x+T_{2}^{(2)}\right) f_{t_{r}}\left(t_{r}\right) d t_{r} f_{x}(x) d x+\int_{0}^{\tau} \int_{t_{r}=T_{2}^{(2)}}^{T_{3}}(x+ \\
\left.t_{r}+x^{\prime}\right) f_{t_{r}}\left(t_{r}\right) d t_{r} f_{x}(x) d x+\int_{0}^{\tau} \int_{t_{r}=T_{3}}^{\infty}\left(x+t_{r}+x / /\right) f_{t_{r}}\left(t_{r}\right) d t_{r} f_{x}(x) d x \\
=\quad\left(\tau+T_{2}^{(1)}\right) e^{-\mu \tau}+\int_{0}^{\tau} \int_{t_{r}=T_{2}^{(2)}}^{T_{3}}\left(x+t_{r}+x^{\prime}\right) \lambda e^{-\lambda t_{r}} d t_{r} \mu e^{-\mu x} d x+\int_{0}^{\tau}\left\{\left(x+x^{/ /}\right) e^{-\lambda T_{3}}+\right. \\
\left.T_{3} e^{-\lambda T_{3}}+\frac{1}{\lambda} e^{-\lambda T_{3}}+\left(x+T_{2}^{(2)}\right)\left(1-e^{-\lambda T_{2}^{(2)}}\right)\right\} \mu e^{-\mu x} d x
\end{gathered}
$$

\subsection{Expected total cost per unit time}

After getting those entire expected cost components, the expected total cost per unit time based on renewal reward theorem can be achieved as follows:

Expected total cost per unit time $=\frac{\text { Expected total cost in a cycle, } \mathrm{E}[\mathrm{TC}]}{\text { Expected cycle length, } \mathrm{E}[\mathrm{T}]}=\frac{\mathrm{E}[\mathrm{I}] * \mathrm{H}+\mathrm{E}[\mathrm{S}] * \delta+\mathrm{E}[\mathrm{L}] * \pi+\mathrm{K}+\mathrm{E}[\mathrm{M}]}{\mathrm{E}[\mathrm{T}]}$

\subsection{Solution procedure}

From the Matlab Optimization Toolbox, fmincon solver with the interior-point algorithm (a constrained non linear optimization solver) is used to solve the mathematical model. The results of the developed model are obtained through numerical experiments. Finally a sensitivity analysis is carried out \& this analysis shows how each individual decision variables, i.e., $\mathrm{R}$ and $\tau$ along with expected total cost, $\mathrm{E}[\mathrm{TC}]$ respond with respect to change of different input parameters.

\section{Numerical example and Sensitivity analysis}

\subsection{Numerical example}

Numerical experiment is carried out in order to illustrate how the derived model performs by considering both production uptime $(\tau) \&$ production reorder point $(\mathrm{R})$. Since the problem is complex \& it is not 
possible to solve the problem analytically. So, the mathematical model is solved using the Matlab optimization toolbox. All parameters are mentioned in the following Table 1.

\section{Table 1}

Input parameters

\begin{tabular}{ccccccc} 
Production rate(production per year) & $P$ & 10,000 & Per unit per year inventory holding cost & $H$ & $\$ 1$ \\
Demand rate(demand per year) & $D$ & 7,500 & Unit shortage cost & $\delta$ & $\$ 20$ \\
Deterioration rate(deterioration per year) & $\theta$ & 0.2 & Unit cost of deteriorated item & $\pi$ & $\$ 1$ \\
Avg. number of m/c breakdown per year & $\mu$ & 0.2 & $\mathrm{M} / \mathrm{c}$ setup cost & $\mathrm{K}$ & $\$ 50$ \\
Avg. number of m/c repair per year & $\lambda$ & 20 & $\mathrm{M} / \mathrm{c}$ repair(maintenance) cost & $\mathrm{M}$ & $\$ 200$ \\
\hline
\end{tabular}

By considering all those input parameters a Matlab program is constructed, and then finally with the aid of fmincon solver of optimization toolbox, the near optimal solution is obtained for this nonlinear optimization problem. The solution for the base case is given as production up tiem $\left(\tau^{*}\right)=0.2957$ years, production reorder point $\left(R^{*}\right)=40.40 \approx 41$ pcs and expected total cost per year $\left(E[T C]^{*}\right)=\$ 1090.36$.

\subsection{Sensitivity analysis}

In order to investigate the behavior of the model, all input parameters are varied one by one. It is possible to observe the sensitivity of the model by changing a single input parameter while keeping other input parameters intact. In the later part of the analysis, the importance of production reorder point $\mathrm{R}$ for the derived model is also explained with necessary illustration.

\subsubsection{Sensitivity analysis with respect to unit shortage cost $\delta$}

From Fig. 10 it can be seen that expected total cost per unit increases as $\delta$ is increased, and $\delta$ has significant impact on the reorder point. If shortage cost is increased, then reorder point becomes high in order to minimize shortage. On the other hand, shortage cost has less impact on the production up time. Production up time is not changing (increasing) significantly due to increase in unit shortage cost.
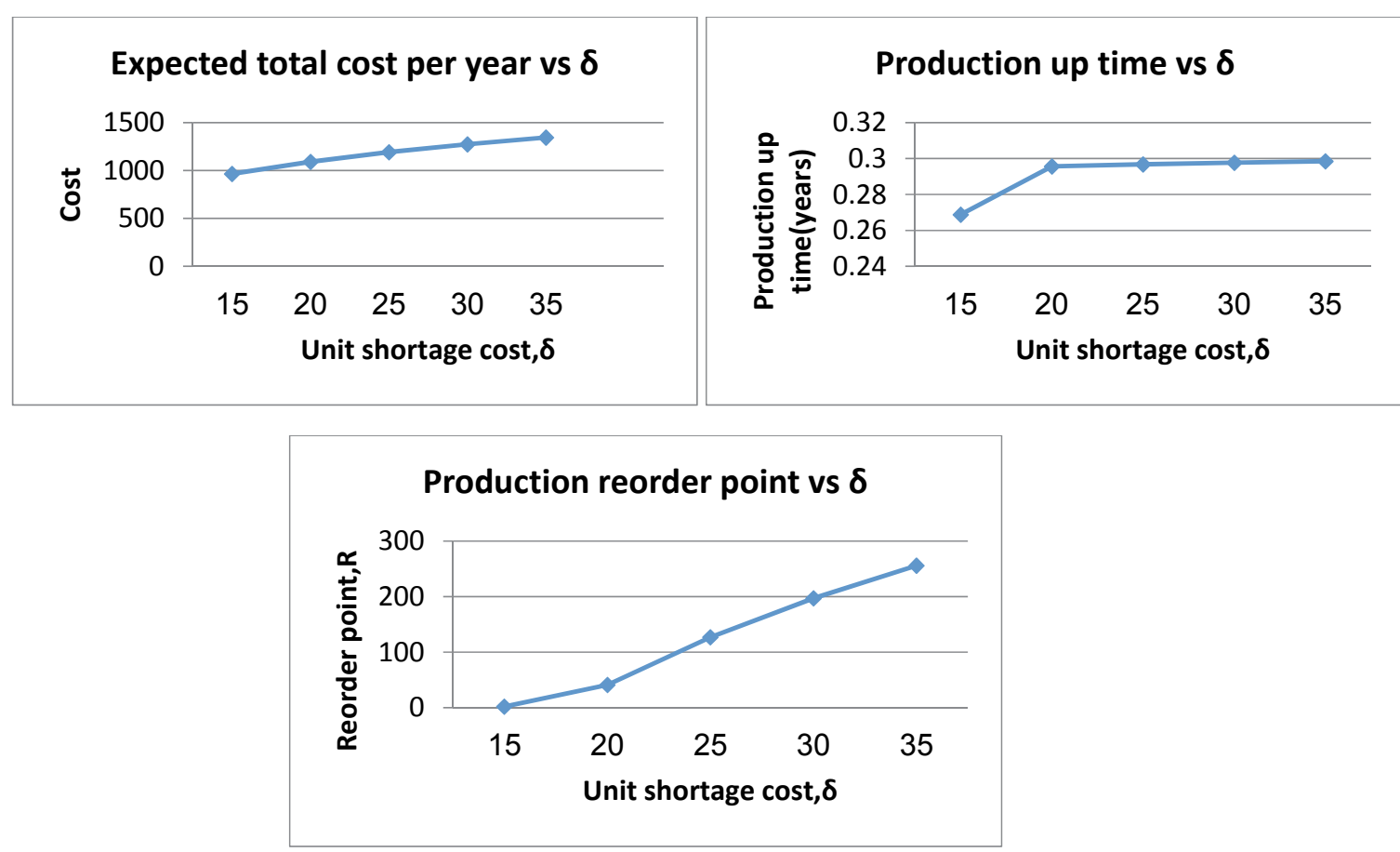

Fig. 10. Expected total cost per year, up time $\&$ reorder point for different value of $\delta$ 


\subsubsection{Sensitivity analysis with respect to repair time $1 / \lambda$}

Sensitivity analysis is performed by varying the repair time while all other parameters remain fixed. From Fig. 11 it can be seen that total cost per unit decreases as $1 / \lambda$ is decreased.
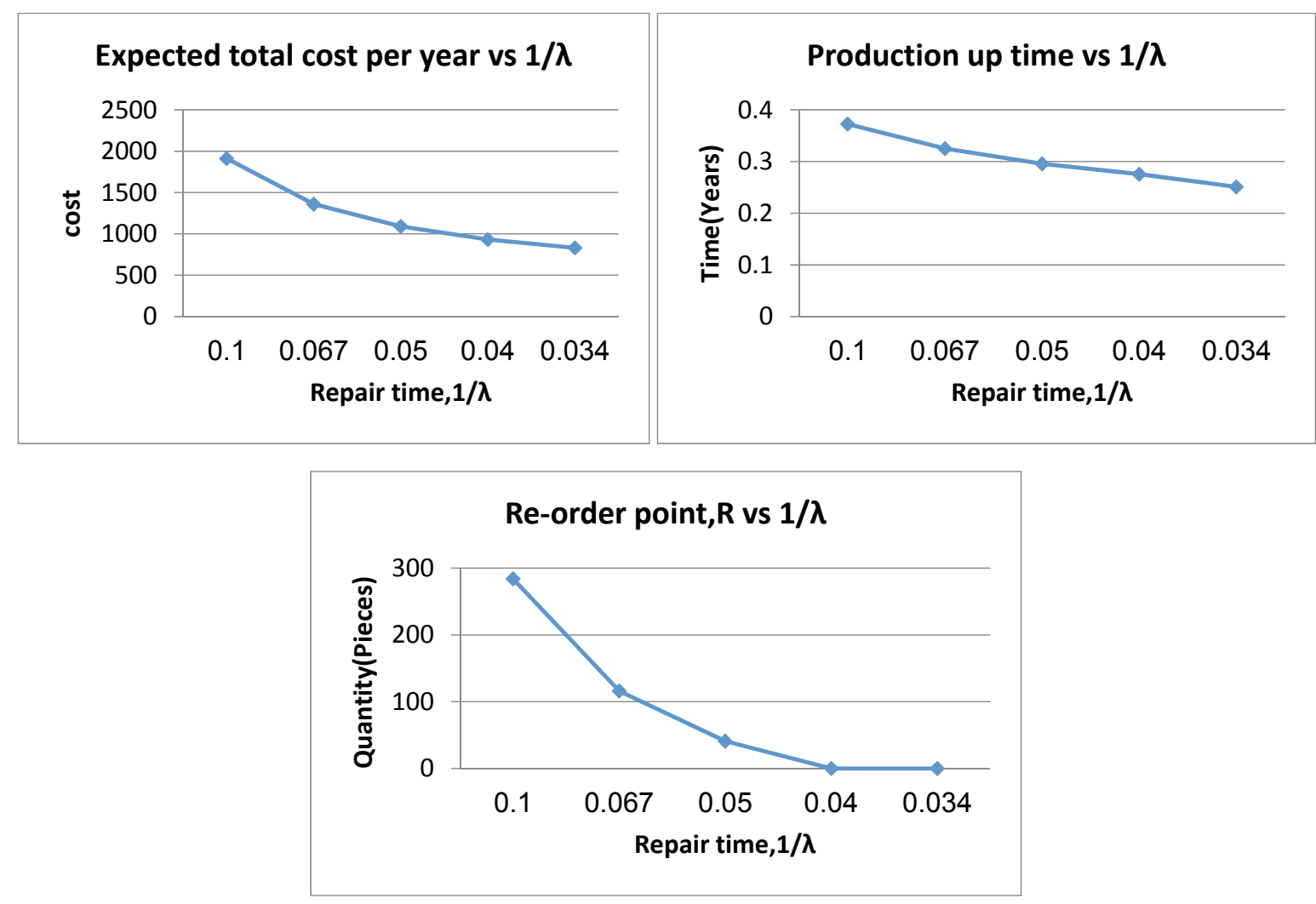

Fig. 11. Expected total cost per year, up time \& reorder point for different value of $1 / \lambda$

One of the main reasons behind this response is that short repair time helps to reduce the probability of shortage, as a result, shortage cost is low and this low shortage cost yields low total cost. $1 / \lambda$ has a significant impact on the reorder point. If repair time is decreased and short then reorder point becomes low\& finally approaches zero, as a result, it helps to minimize the expected value of the total cost by reducing the deteriorating cost. On the other hand, repair time has small impact on the production up time. Production up time is changing (decreasing) slowly due to decrease in repair time.

\subsubsection{Sensitivity analysis with respect to avg. number of $\mathrm{m} / \mathrm{c}$ breakdown $\mu$}

From Fig. 12 it can be seen that total cost per unit increases as $\mu$ increases. It means when number of $\mathrm{m} / \mathrm{c}$ breakdowns per year is increased then it helps to increase $\mathrm{m} / \mathrm{c}$ repair cost results in increasing total cost per year. Moreover, $\mu$ has significant impact on the reorder point. The production reorder point is increased when $\mu$ is increased. This response of $\mathrm{R}$ indicates that when $\mu$ is very high, then high reorder point helps to minimize the shortage quantity \& consequently the total cost of shortage even though it increases deteriorating quantity and deteriorating cost as well. When frequency of $\mathrm{m} / \mathrm{c}$ breakdown is very high, then the frequency of repairing operation is also very high. Since repair time is stochastic \& this stochastic nature of repair time increases the probability of shortage, high reorder point acts as a safety stock while the $\mathrm{m} / \mathrm{c}$ is in repairing mode and still there is a significant demand from customers. On the other hand, we can see interesting response of production up time $\&$ reorder point with respect to $\mu$, when $\mu$ vary (increase) from 0.01 to 0.2 then production up time is increased from 0.1654 to 0.2957 years. Certainly, when the value of $\mu$ is 1 and $>1$ then production up time is decreased, but the production 
reorder point is increased due to increase of $\mu$. Here uptime is decreased from 0.2843 to 0.1231 years and reorder point is increased significantly from 689 to 1540 when $\mu$ varies from 1 to 10 . This response of the model with respect to random breakdown indicates that if the average number of breakdowns is large, then production uptime is increased in order to minimize the probability of shortage but when the number of breakdowns is too large, then long production run time may increase probability of breakdown. This is the reason why production runtime is decreased when the number of machine breakdowns is too many, and as a result, it minimizes the probability of breakdown. Consequently, when the production run time is decreased, though the number of breakdowns is too many, then it also increases the probability of shortage because if the production run time is short then inventory depletion time is also short \& inventory will be depleted early. So if any breakdown occurs and due to the stochastic nature of repair time, significant shortage might be created during the repairing of the machine. As a result, in order to minimize this high shortage, reorder point is increased significantly with the increase of the number of machine breakdowns.
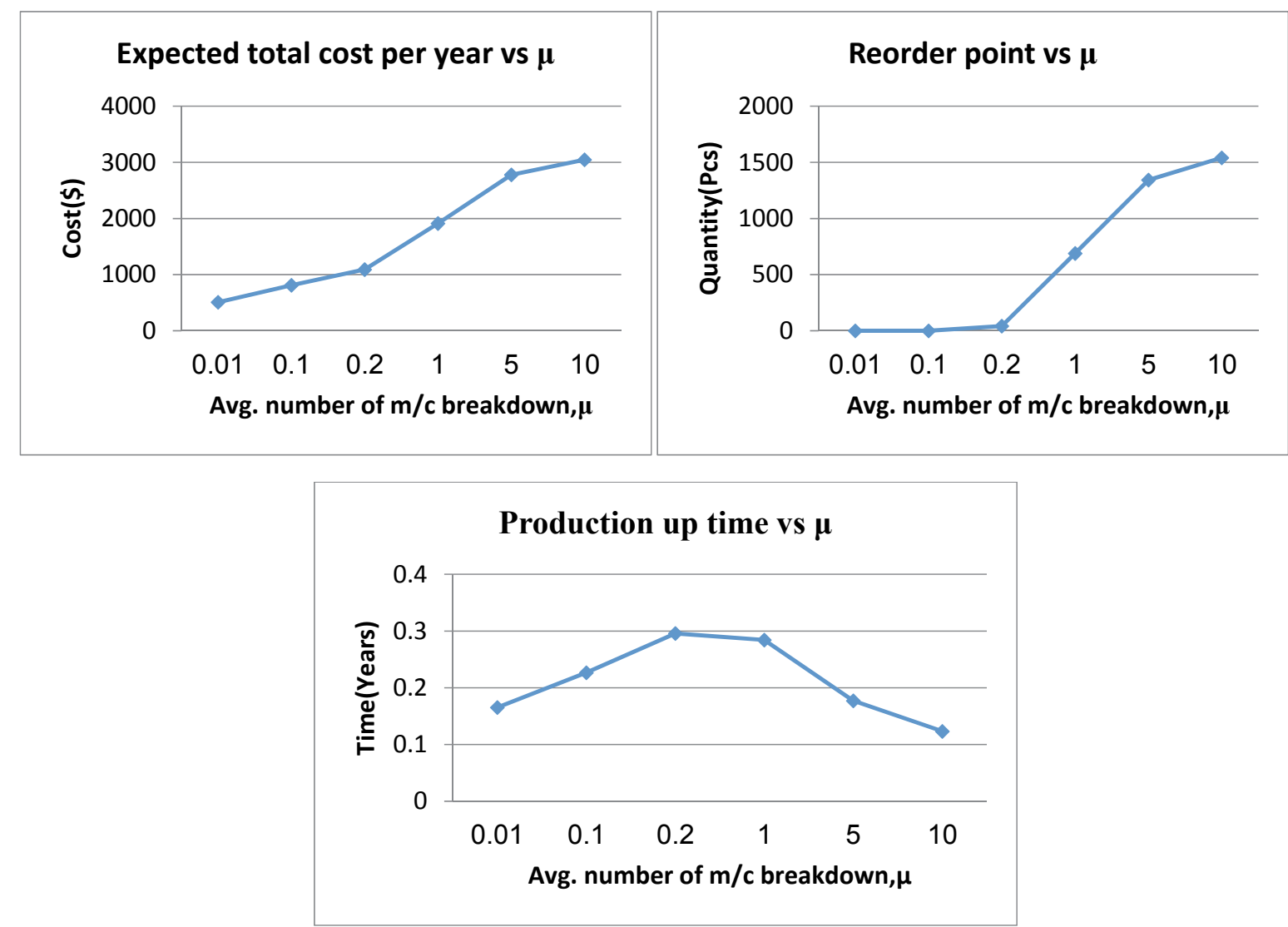

Fig. 12. Expected total cost per year, up time \& reorder point for different value of $\mu$

\subsubsection{Sensitivity analysis with respect to $\mathrm{m} / \mathrm{c}$ setup cost $K$}

From Fig. 13 it can be seen that total cost per unit increases as $K$ is increased. It means when production setup cost is increased then it helps to increase the total cost per year and $K$ also has significant impact on the reorder point. The production reorder point is decreased when $K$ is increased. Finally, it moves towards zero when $K \geq \$ 100$. Net $\mathrm{m} / \mathrm{c}$ setup cost depends on the number of setup operations and if the number of $\mathrm{m} / \mathrm{c}$ setups is increased then net setup cost is also increased .So when a single $\mathrm{m} / \mathrm{c}$ setup is very expensive then it is wise to reduce number of $\mathrm{m} / \mathrm{c}$ setups and increase production run time. That's why production up time is changing (increasing) due to increase in $K$. So this response of $\tau$ indicates that the high value of $K$ leads to a large volume of production and fewer numbers of setups. It can also be 
observed that when production up time is long enough due to high setup cost, then it automatically enforces the reorder point to become 0 .
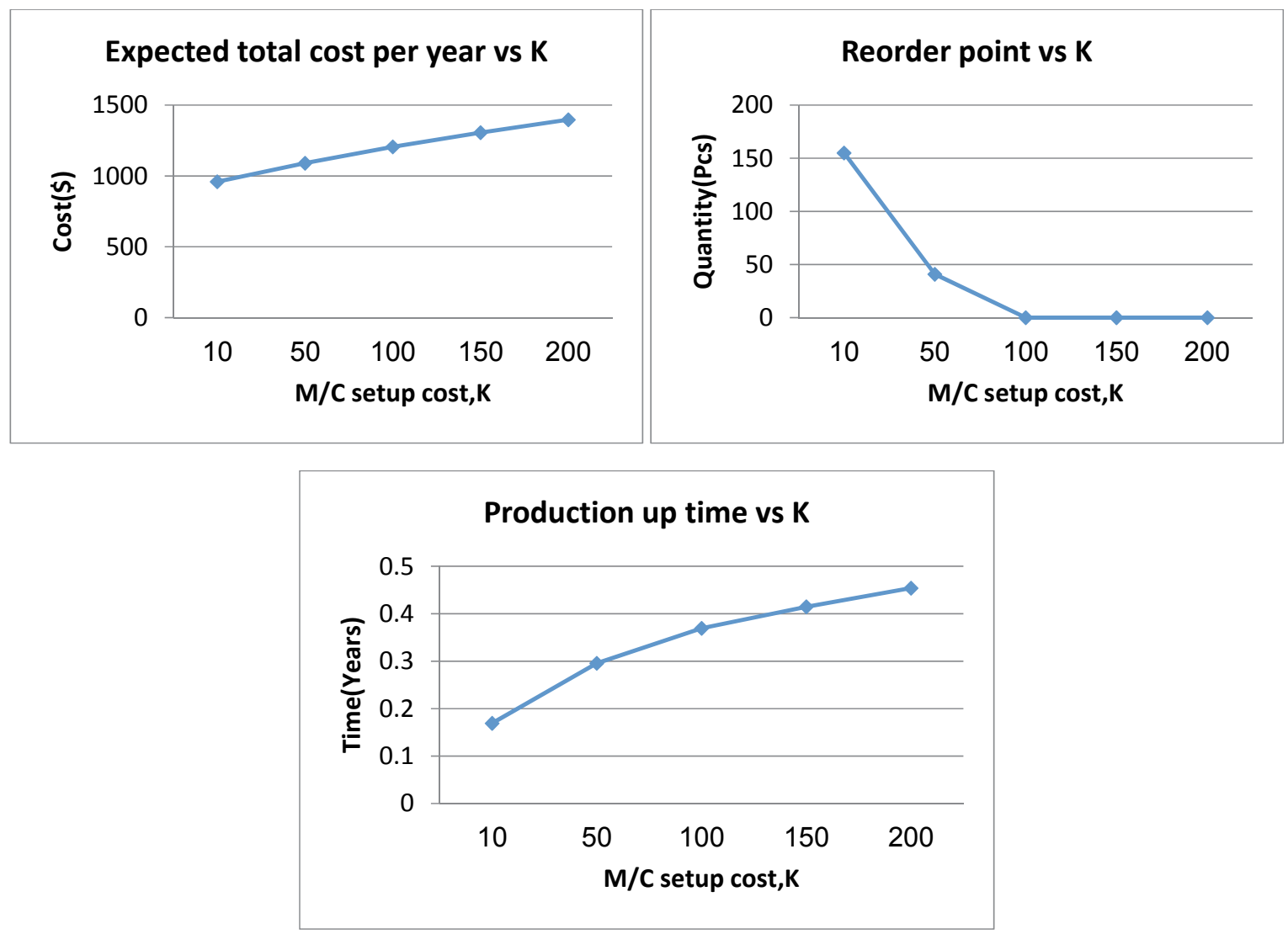

Fig. 13. Expected total cost per year, up time \& reorder point for different value of $K$

\subsubsection{Sensitivity analysis with respect to all other parameters}

From Figs. (14-16) it can be seen that total cost per unit increases as $\theta$ is increased. It means when the deterioration rate is increased then it helps to increase deteriorating cost, and as a result, it increases total cost.

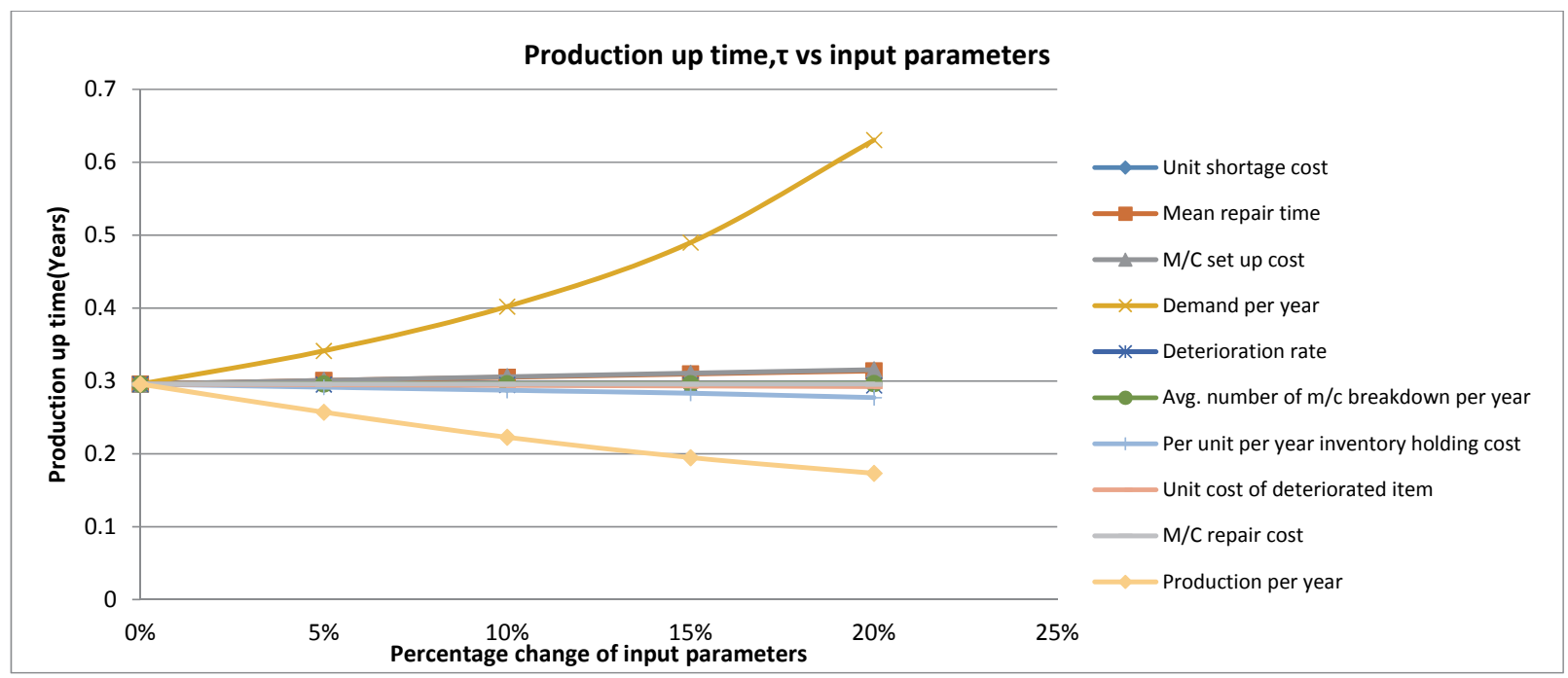

Fig. 14. Sensitivity analysis for production up time 
Furthermore, $\theta$ has significant impact on the reorder point. The production reorder point is decreased when $\theta$ is increased. This response of $\mathrm{R}$ indicates that when the deterioration rate is very high, then low reorder point helps to minimize the deteriorating quantity \& consequently the total cost of deterioration. On the other hand, deterioration rate has small impact on the production up time. Production up time is changing (decreasing) slowly due to increase in deterioration rate. This response of $\tau$ indicates that high rate of deterioration leads to a low volume of production, and hence small generation of deterioration items. The total cost per unit increases as $H$ is increased, it means when per unit per year holding cost is increased then it helps to increase total inventory holding cost, and as a result, it increases total cost per year. Moreover, $H$ has significant impact on the reorder point. The production reorder point is decreased when $H$ is increased. Finally, it moves towards zero when $\mathrm{H}$ is high. This response of $\mathrm{R}$ indicates that when $H$ is very high, then low reorder point helps to reduce the accumulated inventory \& consequently the total cost of inventory. In addition, it helps to decrease deteriorating quantity \& deteriorating cost as well. On the other hand, $H$ has an impact on the production up time. Production up time is changing (decreasing) due to increase in $H$. This response of $\tau$ indicates that the high value of $H$ leads to a low volume of production, and as a result, small generation of accumulated inventory. The total cost per unit increases as $\pi$ is increased, it means when unit cost of deteriorated item is increased then it helps to increase total deteriorating cost, and as a result, it increases total cost per year. $\pi$ also has significant impact on the reorder point. The production reorder point is decreased when $\pi$ is increased. Finally, it moves towards zero when $\pi$ is high. This response of R indicates that when $\pi$ is very high, then low reorder point helps to reduce deteriorating cost. On the other hand, $\pi$ has small impact on the production up time. Production up time is changing (decreasing) slowly due to increase in $\pi$. However, this response of $\tau$ indicates that high value of $\pi$ leads to a low volume of production, and as a result, small generation of deteriorated items. The expected total cost per unit increases as $M$ is increased, it means when $\mathrm{m} / \mathrm{c}$ repair cost is increased then it helps to increase the total cost per year. It is noted that $M$ has no influence on the reorder point $\&$ production up time. Production up time $\&$ reorder point do not change with the increase in repair cost. From Figs. (14-16) it can also be seen that total cost per unit decreases as $P$ is increased; it means when production rate is increased then it helps to decrease production run time, and as a result, expected total cost is decreased. When production rate is increased, the gap between production \& demand is also increased as demand rate is fixed, and consequently, volume of deterioration is also increased. That's why in order to minimize this deteriorating quantity as many as possible; reorder point is moving towards low value with the increase in production rate. Moreover, high rate of production also helps to minimize the probability of shortage as demand rate is still remaining same. Considering this matter, the low reorder point is more appropriate.

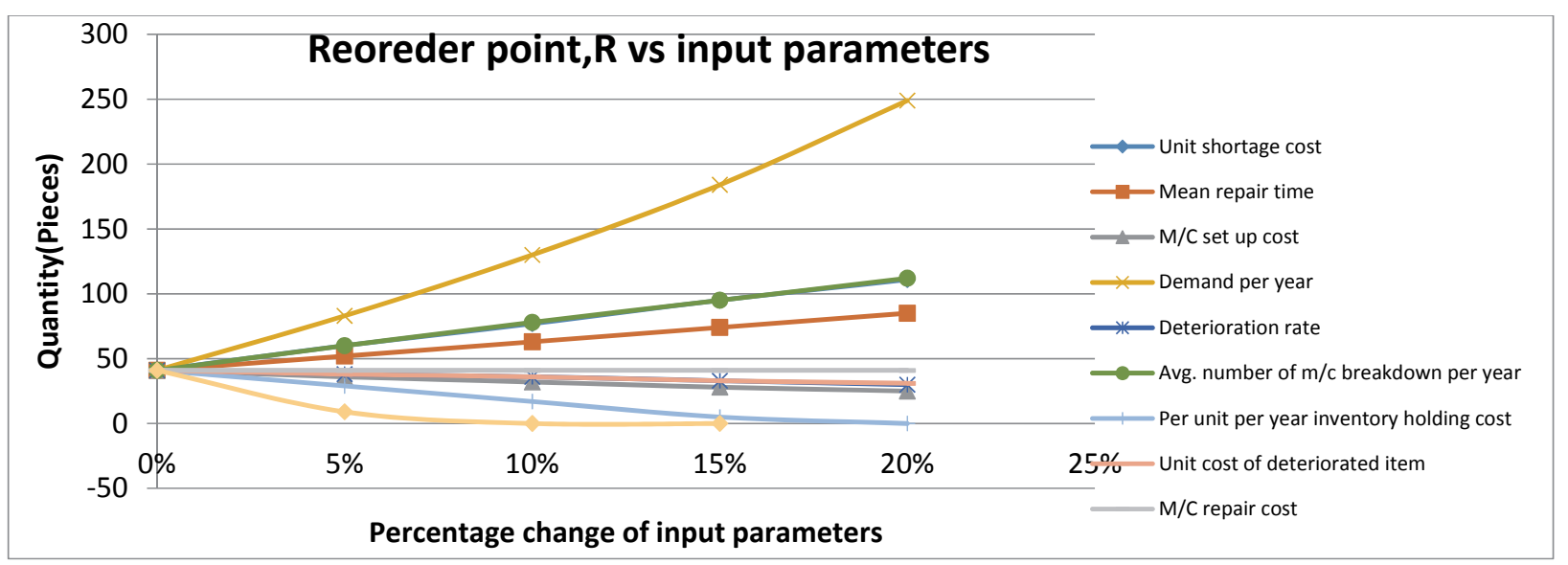

Fig. 15. Sensitivity analyses for production reorder point

Also, the total cost per unit increases as $D$ is increased; it means when the demand rate is increased then it helps to increase production run time, and as a result, expected total cost is also increased. When demand rate is increased, the gap between production $\&$ demand is also decreased as production rate is 
fixed. Consequently, the volume of deterioration is also decreased. Moreover, high rate of demand also increases the probability of shortage as production rate is still remaining same. That's why in order to minimize this shortage quantity as many as possible; reorder point is moving towards high value with the increase in demand rate.

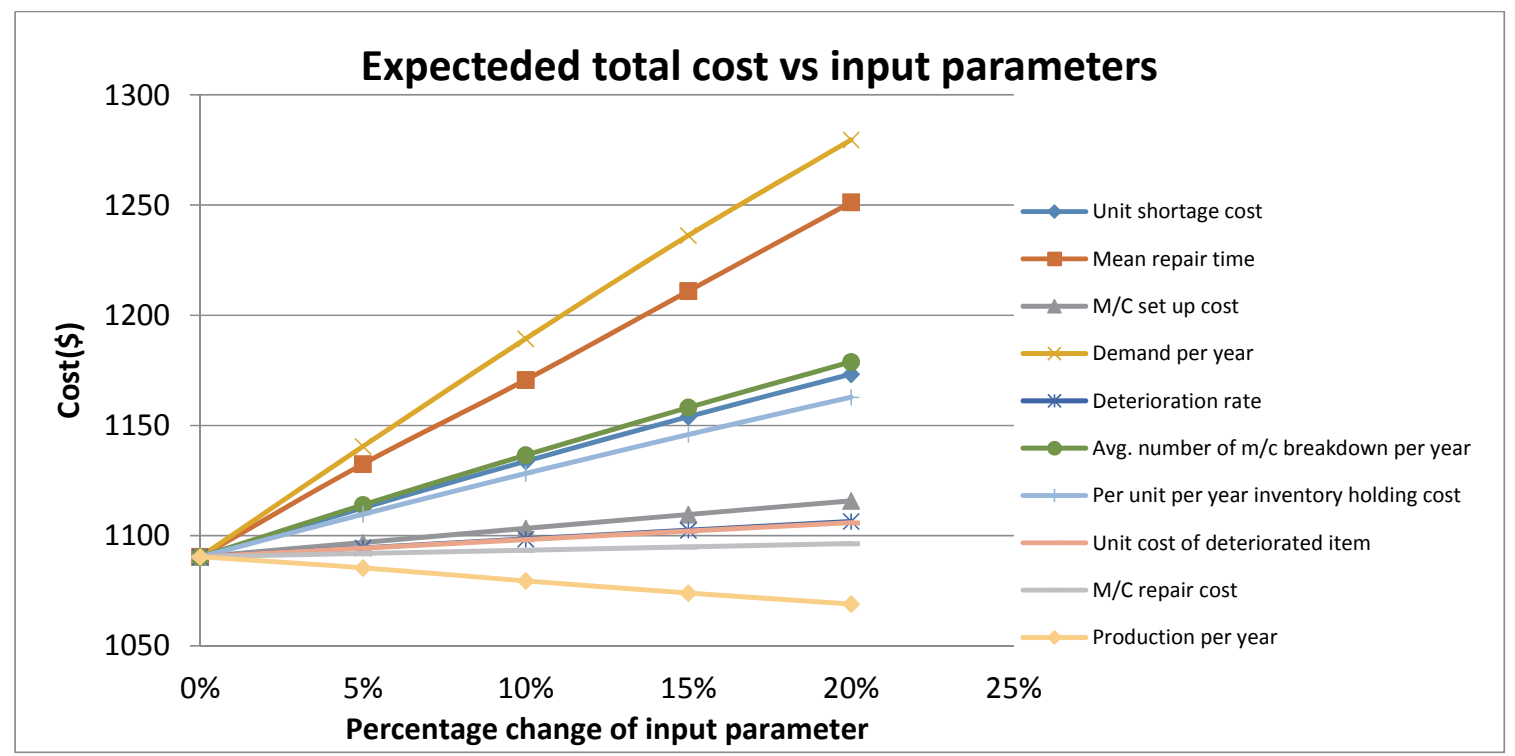

Fig. 16. Sensitivity analysis for expected total cost per unit

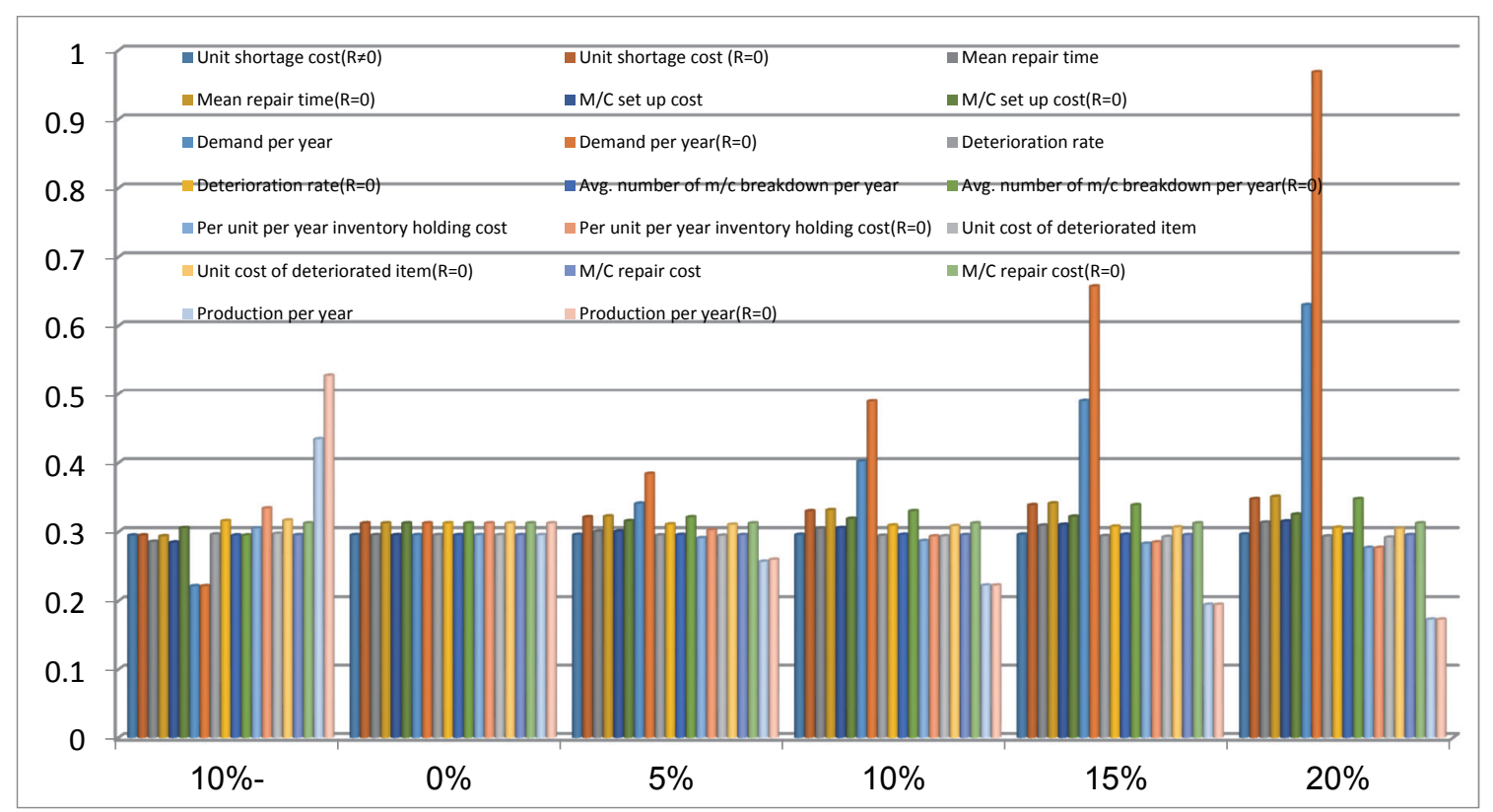

Fig. 17. Comparison of production uptime for percentage change of input parameters

\subsubsection{Impact of $R$ on production up time \& expected total cost when input parameters vary}

Production reorder point $\mathrm{R}$ has a significant impact on the expected total cost $\&$ the production uptime when the input parameter varies. If no reorder point is considered in the proposed model, i.e., $\mathrm{R}$ is fixed and assumed to be zero in the optimization model (Figs. (17-18)) then we get interesting results both for production up time and expected total cost $\&$ these responses are different (under certain circumstances) in comparison to the production inventory model having a production reorder point which is shown in the following Figs. (17-18). 
From Figs. (17-18) it can be observed that when shortage cost is high, machine repair time is high; deterioration rate is low, the number of machine breakdowns is high; inventory holding cost per unit is low, unit cost of deteriorated item is low, the setup cost is low, the production rate is low and the demand rate is high; then production inventory model having a reorder point gives better optimal solutions in comparison to production inventory model with no reorder point. So, from the above analysis \& observations, it is apparent that inclusion of a production reorder point in the perishable productioninventory model is always effective and this reorder point $\mathrm{R}$ will help to reduce the expected total cost.

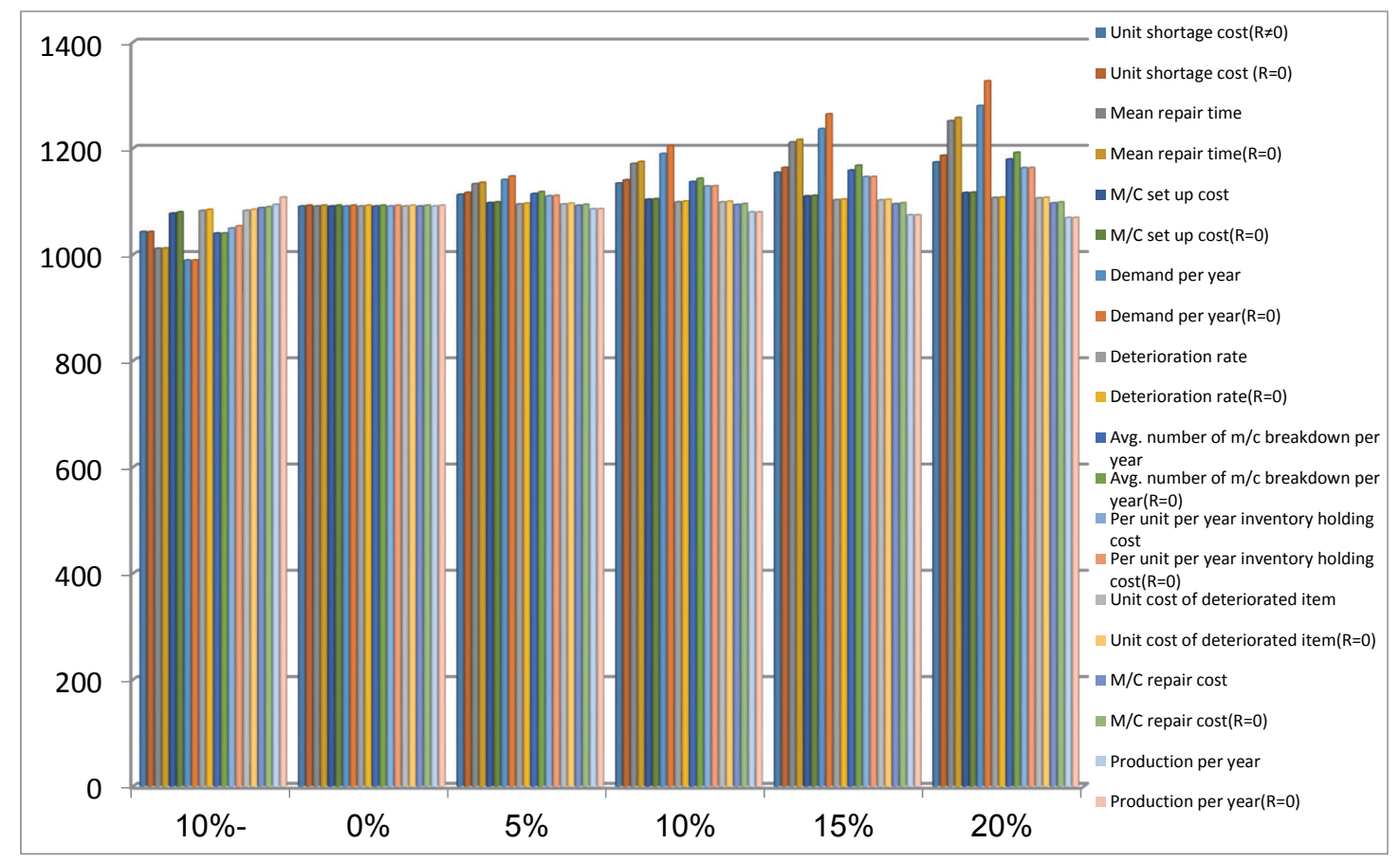

Fig. 18. Comparison of expected total cost per year for percentage change of input parameters

\section{Conclusions and recommendations}

In this paper an integrated production inventory model has been developed for deteriorating items by considering stochastic repair time and random machine breakdown. This research extended the work of Lin and Gong (2006) by introducing a production reorder point to help reduce the expected value of the total cost per unit time. From numerical analysis, it has been found that the production reorder point had significant impact on the total cost function. The model derived in this research can help make a production-inventory decision for the perishable product in a manufacturing environment where machine breakdown cannot be avoided. We tried to derive a proof of the convexity for the objective function. However, due to the complexity of the objective function, it was impossible for us to prove that the objective function is a convex function. This is the main limitation of our research. Anyway, in numerical experiments, we have used multiple starting solutions and the optimization program always converged to the same solutions

\section{References}

Berk, E., \& Gürler, Ü. (2008). Analysis of the (Q, r) inventory model for perishables with positive lead times and lost sales. Operations Research,56(5), 1238-1246.

Chiu, S. W., Wang, S. L., \& Chiu, Y. S. P. (2007). Determining the optimal run time for EPQ model with scrap, rework, and stochastic breakdowns.European Journal of Operational Research, 180(2), 664-676..

Chiu, Y. S. P., Lin, H. D., \& Chang, H. H. (2011). Mathematical modeling for solving manufacturing run time problem with defective rate and random machine breakdown. Computers \& Industrial 
Engineering, 60(4), 576-584.

Gürler, Ü., \& Özkaya, B. Y. (2003). A note on "continuous review perishable inventory systems: models $\&$ heuristics". IIE Transactions, 35(3), 321-323.

Gürler, Ü., \& Özkaya, B. Y. (2008). Analysis of the (s, S) policy for perishables with a random shelf life. Ile Transactions, 40(8), 759-781.

He, Y., Wang, S. Y., \& Lai, K. K. (2010). An optimal production-inventory model for deteriorating items with multiple-market demand. European Journal of Operational Research, 203(3), 593-600.

Liu, L., \& Lian, Z. (1999). (s, S) continuous review models for products with fixed lifetimes. Operations Research, 47(1), 150-158.

Lin, G. C., \& Gong, D. C. (2006). On a production-inventory system of deteriorating items subject to random machine breakdowns with a fixed repair time. Mathematical and Computer Modelling, 43(7), 920-932.

Nahmias, S. (2011). Perishable inventory systems (Vol. 160). Springer Science \& Business Media.

Rau, H., Wu, M. Y., \& Wee, H. M. (2003). Integrated inventory model for deteriorating items under a multi-echelon supply chain environment.International journal of production economics, 86(2), 155-168.

Tekin, E., Gürler, Ü., \& Berk, E. (2001). Age-based vs. stock level control policies for a perishable inventory system. European Journal of Operational Research, 134(2), 309-329.

Tersine, R.J. (1994). Principles of Inventory \& Materials Management. Prentice-Hall International.

Weiss, H. J. (1980). Optimal ordering policies for continuous review perishable inventory models. Operations Research, 28(2), 365-374.

Widyadana, G. A., \& Wee, H. M. (2011). Optimal deteriorating items production inventory models with random machine breakdown and stochastic repair time. Applied Mathematical Modelling, 35(7), 34953508.

Widyadana, G. A., \& Wee, H. M. (2012). An economic production quantity model for deteriorating items with multiple production setups and rework.International Journal of Production Economics, 138(1), 62-67.

Yang, P. C., \& Wee, H. M. (2003). An integrated multi-lot-size production inventory model for deteriorating item. Computers \& Operations Research,30(5), 671-682.

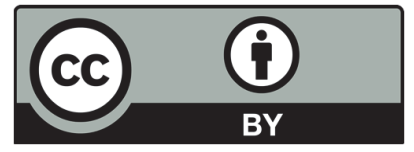

(C) 2016 by the authors; licensee Growing Science, Canada. This is an open access article distributed under the terms and conditions of the Creative Commons Attribution (CCBY) license (http://creativecommons.org/licenses/by/4.0/). 